\title{
Urban wastes to remediate industrial sites: a case of polycyclic aromatic hydrocarbons contamination and a new process
}

\author{
E. Montoneri $\cdot$ L. Tomasso $\cdot$ N. Colajanni $\cdot$ \\ I. Zelano $\cdot$ F. Alberi - G. Cossa $\cdot$ R. Barberis
}

Received: 11 April 2012/Revised: 16 January 2013/Accepted: 13 February 2013/Published online: 23 March 2013

(C) Islamic Azad University (IAU) 2013

\begin{abstract}
The objective of the present paper was to investigate the potential of urban wastes derived soluble bioorganic substances (SBO) to perform as auxiliaries for enhanced washing of urban soil contaminated by industrial activities. The second objective was to show how the SBO could be used for remediating the environmental impact caused by industrial activities and, at the same time, be compatible with the real-world situation demanding zero waste processes. The SBO, isolated from four urban biowastes, were characterized for their lipophilic/hydrophilic (LH) and aliphatic/aromatic $\mathrm{C}$ ratios, and for their surface activity properties. Soil, containing about $0.45 \%$ $\mathrm{w} / \mathrm{w}$ polycyclic aromatic hydrocarbons (PAHs), was sampled from a dismissed coal gasification site. The efficiency of the SBO for washing the contaminated soil was investigated. The most lipophilic SBO, in spite of the highest surface activity, was the least efficient. The products having lower LH, poorer surface activity, but higher concentration of aromatic $\mathrm{C}$ were more efficient. All SBO allowed
\end{abstract}

E. Montoneri $(\square) \cdot$ L. Tomasso · N. Colajanni · I. Zelano

Dipartimento di Chimica,

Università di Torino, Via P. Giuria 7,

10125 Turin, Italy

e-mail: enzo.montoneri@unito.it

F. Alberi - G. Cossa

Dipartimento di Alessandria,

ARPA Piemonte, Polo Bonifiche,

Spalto Marengo 33,

15100 Alessandria, Italy

R. Barberis

ARPA Piemonte, Area Funzionale Tecnica,

Via Pio VII 9, 10135 Turin, Italy developing a two steps process. This comprised soil washing, and the recovery and chemical treatment of the washing solution, to yield a PAHs-SBO precipitate and the clean water phase to recycle to further soil washing. Data were obtained under the same experimental conditions using Triton X-100 commercial surfactant. The results indicated that, although the commercial surfactant is the most efficient in the soil washing step, it does not allow removal of PAHs from the recovered washing solution. On the contrary, 95-99\% PAHs removal from the recovered SBO washing solutions is attained.

Keywords Biosurfactants - Environment - Remediation · Biomass · Soil · Washing

\section{Introduction}

Urbanization has caused concentration of population and industrial activities in metropolitan areas, with consequent environmental impact deriving from increasing municipal refuse, and soil and water contamination from industrial wastes. Although human consumption habits and industrial activities may appear to impact negatively the urban context in a synergic way, the concentration of biowastes has a potential beneficial fall out for the same urban context. Recent work reports how, through urbanization and municipal collection practices, urban bio-wastes (UBW) have become a low entropy sustainable source of both energy and materials for the chemical industry and society. Indeed, UBW are shown a cost-effective (Montoneri et al. 2011a) source of a wide range of soluble bioorganic substances (SBO), having similar origin and chemical nature as natural soil-organic matter (NOM), good properties as anionic surfactants and, therefore, the potential to be used 
as ecofriendly chemical auxiliaries in a number of important technological applications, where synthetic chemicals are currently used. Papers have been published reporting the performance of SBO in textile detergency (Savarino et al. 2010) and dyeing (Savarino et al. 2009), in the treatment of polluted effluents from industrial chemical processes (Avetta et al. 2012), in water emulsification and in metal oxides flocculation (Montoneri et al. 2009), in soil fertilization for agricultural purpose (Sortino et al. 2012), and as templates for the synthesis of porous materials with tailored morphology (Magnacca et al. 2012). These diversified applications prospected the possibility to turn a urban wastes treatment plant into biorefinery for the production of value-added bio-based chemicals (Montoneri et al. 2011a). Thus, they stimulated further work on SBO to assess how broad the range of their applications was. Remediation of urban contaminated sites was a further worthwhile application for investigation, as demonstrated by the large amount of literature dealing with the remediation of contaminated soil problems (Chang and Li 2009; Huang et al. 2006; Li et al. 2006; Wu et al. 2005; Zhang et al. 2008).

To test the performance of the above SBO in environmental remediation, a soil containing about $0.45 \% \mathrm{w} / \mathrm{w}$ polycyclic aromatic hydrocarbons (PAHs) and over $5 \%$ $\mathrm{w} / \mathrm{w}$ organic $\mathrm{C}$ was selected. This soil was sampled from an industrial site in the city of Torino (Italy), hosting a plant for the production of gas fuel from coal which had been established in 1837 and was dismissed in late 1960s. For the nature and concentration of the contaminants, and the content of organic matter, the soil was representative of typical and most challenging contaminated areas spread worldwide. The PAHs are indeed widely diffuse contaminants. Their presence in the environment is mainly due to the waste discharged from industrialized and urbanized areas, coal tar pavement, off-shore petroleum hydrocarbon production or petroleum transportation (Froehner et al. 2012a). Several methods are available for PAHs treatment, such as aerobic degradation (Baboshin and Golovleva 2012), anaerobic degradation (Zhang et al. 2012), ultrasonic degradation (Bremner et al. 2011), electroremediation (Pazos et al. 2010), and surfactant assisted soil washing (Dermont et al. 2000; Jafvert 1996). The PAHs biodegradation is carried out by bacteria, fungi, and plants (Baboshin and Golovleva 2012). This technology is based on the capacity of microorganisms to use bioavailable PAHs as growth substrates and mineralize them. However, not all the substrate in the ecosystem is available to microorganisms. For examples, most of the soil pore volume is inaccessible for bacterial cells for reasons of geometry. In addition, high PAHs concentration or biodegradation intermediates may be toxic and inhibit microorganisms' growth. Electroremediation is based on the application of the electric current to promote the movement of contaminants (Pazos et al. 2010). Soil decontamination from PAHs by this technique is in an initial stage. Use of electroremediation in combination with other biological and/or physical-chemical techniques may allow developing more efficient technologies. Ultrasonic degradation (Bremner et al. 2011) is based on ultrasound capable to promote advanced oxidation processes by generating key oxidants such as hydroxyl radicals. Generally, this technique is described as a powerful mean of remediating water contaminated with organic pollutants. Surfactant-assisted soil washing is accomplished by washing soil with an aqueous surfactant solution. This technology is based on the capacity of water soluble surfactant molecules to lower the soil-water interfacial tension, to micellize in water solution, and so to ease out the transfer of the contaminant from the soil into the surfactant hydrophobic micellar core present in aqueous phase. This process, however, requires secondary treatment of the after userecovered aqueous solution. For soil washing, the SBO appeared to be the ideal compounds which could perform either in the primary step of contaminant extraction from soil and in the secondary step of contaminant removal from the recovered washing solution. Indeed, previous work demonstrated for SBO good surfactant properties and capacity to enhance the solubility of hydrophobic organic molecules in water (Montoneri et al. 2010). Also, these substances were demonstrated to be soluble at $\mathrm{pH}>4$ and to precipitate at lower $\mathrm{pH}$. Thus, it appeared that they could be used in soluble form to help the transfer of the contaminant into the aqueous washing solution and then precipitated at acid $\mathrm{pH}$ together with the contaminant to yield a solid phase containing the contaminant and a clean aqueous solution to recycle to further use.

The objective of the present paper was to assess the potential of SBO to perform as auxiliaries for surfactantenhanced soil washing by virtue of their surfactant properties. The second objective was to show how the SBO could be used for remediating the environmental impact caused by industrial activities and, at the same time, be compatible with the real-world situation demanding zero waste processes. To these purposes, four different UBW were sampled from a plant in the province of Torino (Italy) performing anaerobic and aerobic digestion. These materials were then processed by alkaline hydrolysis to isolate four chemically different SBO types, which were characterized and used to wash the selected PAHs contaminated soil. As the investigated soil had a rather high content of organic C (over $5 \%$ ), its decontamination by SBO assisted 
soil washing was rather challenging. According to previous work (Froehner et al. 2012b), soil and sediments with high organic carbon content have higher capacity to retain PAHs. Under these circumstances, to accomplish the two above objectives, the reported experimental plan was designed to establish source-product performance relationships and to develop a two steps process, comprising soil washing and secondary treatment of the recovered washing solution. The work was performed from January 2010 through June 2011 in the authors' laboratories.

\section{Materials and methods}

\section{Surfactant acquirement and characterization}

The investigated SBO were sourced from UBW sampled from the process lines of ACEA Pinerolese waste treatment plant in Pinerolo (Italy). The UBW were the digestate (FORSUD) recovered from the plant biogas production reactor fed with the organic humid fraction from separate source collection of urban refuse, and three other materials obtained in the compost production section from different bioresidues: i.e. (i) $\mathrm{CV}$ obtained from urban vegetable $(V)$ residues aged for 230 days, (ii) CVD obtained from FORSUD and V mix aged for 110 days, and (iii) CVDF obtained from FORSUD, $\mathrm{V}$ and municipal sewage sludge $(\mathrm{F}) \mathrm{mix}$ aged for 110 days. The UBW were processed further in a pilot plant (Montoneri 2007) made available from Studio Chiono e Associati in Rivarolo Canavese, Italy. This comprised an electrically heated mechanically stirred $500 \mathrm{~L}$ reactor, a $102 \mathrm{~cm}$ long $\times 10.1 \mathrm{~cm}$ diameter polysulfone ultrafiltration (UF) membrane with $5 \mathrm{kD}$ molecular weight cut-off supplied by Idea Engineering s.r.l. from Lessona (Bi), Italy, and a forced ventilation drying oven. According to the operating experimental conditions, UBW were reacted $4 \mathrm{~h}$ with $\mathrm{pH}$ 13 water at $60{ }^{\circ} \mathrm{C}$ and $4 \mathrm{~V} / \mathrm{w}$ water/solid ratio. The liquid/ solid mix was allowed to settle to separate the supernatant liquid phase containing the soluble UBW hydrolysate from the insoluble residue. The recovered liquid phase was circulated at $40 \mathrm{~L} \mathrm{~h}^{-1}$ flow rate through the UF membrane operating with tangential flow at 7 bar inlet and 4.5 bar outlet pressure to yield a retentate with 5-10\% dry matter content. The concentrated retentate was finally dried at $60{ }^{\circ} \mathrm{C}$. The solid SBO product obtained in $15-30 \% \mathrm{w} / \mathrm{w}$ yield, relatively to the starting UBW dry matter, was characterized according to the previously reported procedure (Montoneri et al. 2011b). Product surface activity properties were determined as previously reported (Montoneri et al. 2010). The product data are reported in Tables 1 and 2. Triton X-100 (CAS number 9002-93-1) was supplied by Sigma Aldrich and used as purchased.

\section{Soil sampling and characterization}

The investigated soil sample $\left(500 \mathrm{~kg}, 0.4 \mathrm{~m}^{3}\right)$ was excavated in 2008 at a depth of $5 \mathrm{~m}$ in the Italgas dismissed industrial site in the city Torino. This soil was likely to be at the surface at the time the gas production installation was operating. A first $30 \mathrm{~kg}$ aliquot was withdrawn from the sampled soil after accurate mechanical homogenization. This was sieved to $2 \mathrm{~cm}$ according to Italian legislation (Presidente della Repubblica 2006) to yield a second $20 \mathrm{~kg}$ aliquot. The $2-\mathrm{cm}$ sieved aliquot was dried 10 days at room temperature in the laboratory, homogenized further by a rotating cylindrical mixer and sieved at $2 \mathrm{~mm}$ to yield a third $6 \mathrm{~kg}$ aliquot. A final $400 \mathrm{~g}$ soil sample was withdrawn from the above third aliquot, dried at $60^{\circ} \mathrm{C}$ for $24 \mathrm{~h}$ at constant weight, ground in a laboratory ball mill and $0.5 \mathrm{~mm}$ sieved to yield the final sample which was randomly sampled for analytical purposes and for running the washing trials. Soil texture, $\mathrm{pH}$, total organic $\mathrm{C}$ and $\mathrm{N}$ content were determined on the $2 \mathrm{~mm}$ sieved sample according to literature (Faithfull 2002; Ministero delle Politiche Agricole 1997, 1999a). The total PAHs soil content was determined on the $0.5 \mathrm{~mm}$ homogenized lot according to EPA8270 procedure (United States Environmental Protection Agency 2007a) by extracting the soil with $\mathrm{CH}_{2} \mathrm{Cl}_{2}$ and gas chromatography/mass spectrometry analysis of the single hydrocarbons listed in Table 3, using a $30 \mathrm{~m}$ length, $0.25 \mathrm{~mm}$ internal diameter, $0.25 \mu \mathrm{m}$ film thickness Rxi-5Sil MS capillary column. Instrumental response vs. concentration plots were obtained for each PAH using $\mathrm{CH}_{2} \mathrm{Cl}_{2}$ solutions spiked with each element in the 20-2,000 ppb range. The detection limit of each PAH was $20 \mathrm{ppb}$. These solutions were analyzed weekly to keep control of the instrumental calibration plots. The soil analysis was performed on $1 \mathrm{~g}$ dried sample. This was treated with $\mathrm{CH}_{2} \mathrm{Cl}_{2}$ by the EPA 3545A pressurized fluid extraction method (United States Environmental Protection Agency 2007b) using the Dionex ASE 200 system. The recovered solvent was added with anhydrous sodium sulfate, filtered and evaporated to $10 \mathrm{ml}$ in a rotary evaporator operated at $40{ }^{\circ} \mathrm{C}, 600 \mathrm{mbar}$ and $60-80 \mathrm{rpm}$. This solvent aliquot was eventually diluted to obtain the PAHs in the same concentration range at which the instrumental calibration was performed. The analytical accuracy was evaluated by spiking the soil sample with each of the 12 analyzed PAHs at 98, 164, 446 and $961 \mathrm{mg} \mathrm{kg}^{-1}$ amounts, then performing the analysis of the spiked soil as above, 


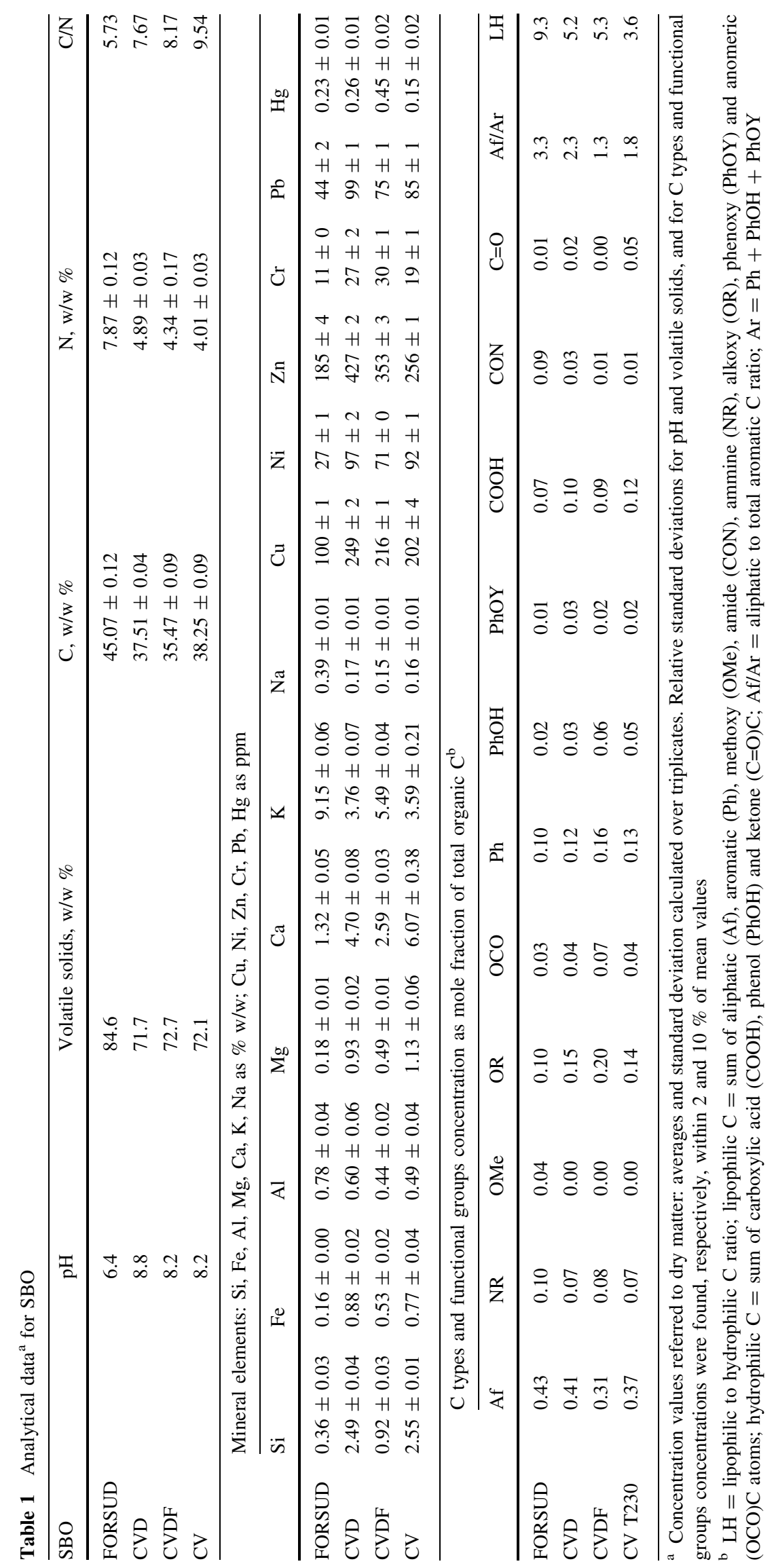


Table 2 Data calculated from experimental surface tension measurements (Fig. 1) for SBO

\begin{tabular}{|c|c|c|c|c|c|c|}
\hline SBO acronym & $-\mathrm{d} \gamma_{1} / \mathrm{dCs}^{\mathrm{a}}$ & $R_{1}^{\mathrm{a}}$ & $\mathrm{Cs}_{1}^{\mathrm{b}}$ & $\gamma_{\mathrm{Cs} 1^{\mathrm{c}}}$ & $-\mathrm{d} \gamma_{2} / \mathrm{dCs}^{\mathrm{a}}$ & $R_{2}^{\mathrm{a}}$ \\
\hline $\mathrm{CV}$ & $5.0 \pm 0.5(0-2 ; 4)$ & 0.971 & 2.1 & 61.2 & $0.94 \pm 0.12(2-9.76 ; 5)$ & 0.938 \\
\hline CVD & $2.7 \pm 0.3(0-3 ; 3)$ & 0.978 & 3.1 & 63.4 & $1.10 \pm 0.08(3-10 ; 18)$ & 0.967 \\
\hline CVDF & $5.3 \pm 0.7(0-3 ; 3)$ & 0.999 & 3.1 & 61.8 & $0.42 \pm 0.05(3-10 ; 8)$ & 0.969 \\
\hline FORSUD & $11.5 \pm 0.9(0-1 ; 3)$ & 0.995 & 1.0 & 48.9 & $0.68 \pm 0.06(1-10 ; 8)$ & 0.749 \\
\hline
\end{tabular}

${ }^{a}$ Slope values $\left(\mathrm{d} \gamma_{\mathrm{i}} / \mathrm{dCs}, \mathrm{mN} \mathrm{L} \mathrm{m}^{-1} \mathrm{~g}^{-1}, i=1,2\right)$ and standard deviations for the two linear tracts of each $\gamma$-Cs plot shown in Fig. 1, associated linear regression coefficient $\left(R_{i}, i=1,2\right)$, and between parenthesis concentration range followed by number of experimental points in the regression analysis

${ }^{\mathrm{b}}$ Concentration $\left(\mathrm{g} \mathrm{L}^{-1}\right)$ at which slope change occurs

${ }^{c}$ Surface tension value at slope change point

Table 3 Physicochemical data of Torino Italgas soil referred to dry matter

\begin{tabular}{ll}
\hline $\mathrm{pH}$ & $6.8 \pm 0.10$ \\
Organic C, \% w/w & $5.29 \pm 0.19$ \\
Organic N, \% w/w & $0.15 \pm 0.01$ \\
$\mathrm{C} / \mathrm{N}$ & $35.3 \pm 2.3$ \\
Coarse sand $(0.2-2 \mathrm{~mm}), \% \mathrm{w} / \mathrm{w}$ & $60.6 \pm 1.8$ \\
Fine sand $(0.05-0.2 \mathrm{~mm}), \% \mathrm{w} / \mathrm{w}$ & $23.6 \pm 1.4$ \\
Coarse silt $(0.02-0.05 \mathrm{~mm}), \% \mathrm{w} / \mathrm{w}$ & $5.5 \pm 0.7$ \\
Fine silt $(0.002-0.02 \mathrm{~mm}), \% \mathrm{w} / \mathrm{w}$ & $8.7 \pm 1.8$ \\
Clay $(<0.002 \mathrm{~mm}), \% \mathrm{w} / \mathrm{w}$ & $1.6 \pm 0.4$ \\
Total PAHs ${ }^{\mathrm{a}}, \mathrm{mg} \mathrm{kg}^{-1}$ & $4,444 \pm 400$ \\
\hline
\end{tabular}

${ }^{a}$ Sum of the following single hydrocarbon average concentration $\mathrm{mg} \mathrm{kg}^{-1}$ values: phenanthrene 393.1 , anthracene 137.5 , fluoranthene 930.0, pyrene 692.8 , benz[a]anthracene 377.6 , chrysene 369.2 , benzo[b]fluoranthene 331.9 , benzo[k]fluoranthene 328.1 , benzo[a]pyrene 336.7, indeno[1.2.3-c.d]pyrene 264.8, dibenzo[a.h]anthracene 57.7, benzo[g.h.i]perylene 224.4

subtracting the PAHs concentration found in the un-spiked soil sample from the analyzed concentration of the spiked sample, and checking the obtained value against the amount of the spiked PAHs. In this fashion the \% recovery of the spiked PAHs was found to be $83 \pm 8$ across the four spike levels. This value was used to correct the soil PAHs concentration values obtained by the above analytical procedure to the true PAHs values.

Soil washing

Soil washing was performed similarly to a previously reported procedure (Deshpande et al. 1999). A soil aliquot $(5 \mathrm{~g})$, taken randomly from the $0.5 \mathrm{~mm}$ sieved homogenized lot, was suspended in the surfactant washing solution $(50 \mathrm{ml})$ and shaken for $24 \mathrm{~h}$ at 150 cycles per min. After $2 \mathrm{~h}$ resting, the suspension was centrifuged and the collected liquid phase was analyzed for total PAHs content by extraction with $\mathrm{CH}_{2} \mathrm{Cl}_{2}$ and $\mathrm{GC}$ analysis (as above) of the separated organic phase. The washing solutions were prepared by dissolving the surfactant in water to $5 \%$ concentration. Four consecutive washing trials were run on each soil sample, each trial performed in triplicates with fresh $5 \%$ surfactant solution on the soil recovered from the previous washing run. Each washing solution sample was collected after use, extracted with $\mathrm{CH}_{2} \mathrm{Cl}_{2}$ and analyzed for its PAHs content to monitor the change of the PAHs concentration from one washing trial to the next one. At the end of fourth washing of the trial, the recovered soil sample was analyzed for residual PAHs by the same procedure used for the starting soil. Total organic $\mathrm{C}$, in the fresh and after use-recovered washing solutions, was measured according to literature (Ministero delle Politiche Agricole 1999b). The PAHs content in the after use-recovered aqueous surfactant solutions was determined on $1 \mathrm{~mL}$ sample. This was extracted sequentially with two $40-50 \mathrm{ml}$ $\mathrm{CH}_{2} \mathrm{Cl}_{2}$, aliquots which, after use, were collected together, and treated and analyzed as reported for the soil analysis.

Treatment of after use-recovered washing solution

An aliquot $(10 \mathrm{ml})$ of the combined washing solutions, recovered from the four consecutive washing trials performed with the same surfactant type on the same soil sample, at $\mathrm{pH} 7.5-8.6$ was acidified with 70-400 $\mu$ l concentrated $\mathrm{HCl}$ to $\mathrm{pH} 1.1-1.3$, diluted to $100 \mathrm{ml}$ and centrifuged. The supernatant liquid phase was analyzed for PAHs as described above.

\section{Results and discussion}

The investigated SBO products are hereinafter referred to by the acronyms of their sourcing UBW: i.e. FORSUD, 
CV, CVD and CVDF. As evidenced by the data reported in Table 1, these products are mainly organic materials, containing $15-28 \%$ mineral matter. The products, obtained by UBW alkaline hydrolysis and filtration through polysulfone membrane (see "Materials and methods"), are hydrolysates with molecular cut-off above 5,000 D. They contain water soluble polymeric molecules which, according to previous work (Montoneri et al. 2011b), may range up to several hundred $\mathrm{kg} \mathrm{mol}^{-1}$. Due to their complexity, SBO cannot be characterized as well as synthetic molecules. Their chemical nature can at best be identified by the concentration of $\mathrm{C}$ types and functional groups reported in Table 1. These organic moieties are the likely memory of the main constituents of the sourcing bioorganic refuse matter which are not completely mineralized during aging under fermentation conditions. For this reason, SBO may be considered to be the pristine material of natural soil-organic matter formed under longer aging conditions. Thus, the structural similarities between SBO and NOM are not surprising. The behavior of these substances as a function of chemical composition cannot be understood, as well as for synthetic single molecules. The $\mathrm{C}$ types and functional groups reported in Table 1 are likely to be not homogeneously distributed over the entire molecular pool. Under these circumstances, to investigate the product-performance relationship, the SBO have been ranked by the two empirical $\mathrm{LH}$ and $\mathrm{Af} / \mathrm{Ar}$ parameters defined in Table 1. Based on these definitions, LH provides an indication of the degree of lipophilicity and Af/Ar is an index of the type of lipophilicity.

For the purpose of this work, the SBO products were also characterized for their surface activity properties in aqueous solution yielding the surface tension $(\gamma)$ vs. added SBO concentration (Cs) plots shown in Fig. 1. As previously reported (Montoneri et al. 2010), these measurements provide hints on the molecular conformation of the investigated substances, on their capacity to enhance the water solubility of hydrophobic compounds, and thus on the experimental conditions to use in the specific case study reported in this work. Figure 1 shows different plots for the investigated SBO. The FORSUD SBO seems to lower water surface tension much more than the other three SBO. To appreciate better these differences, each $\gamma-$ Cs plot was divided into two tracts which were analyzed by linear regression. Table 2 reports the slope values extrapolated from each plot $\left(\mathrm{d} \gamma_{i} / \mathrm{dCs}, \mathrm{mN} \mathrm{L} \mathrm{m}^{-1} \mathrm{~g}^{-1}\right.$, $i=1,2)$ and the associated linear regression coefficient $\left(R_{i}, i=1,2\right)$, together with the concentration $\left(\mathrm{Cs}_{1}\right)$ at which the slope change occurs and the corresponding surface tension value $\left(\gamma_{\mathrm{Cs}_{1}}\right)$. The high $R_{i}$ values $(\geq 0.90)$

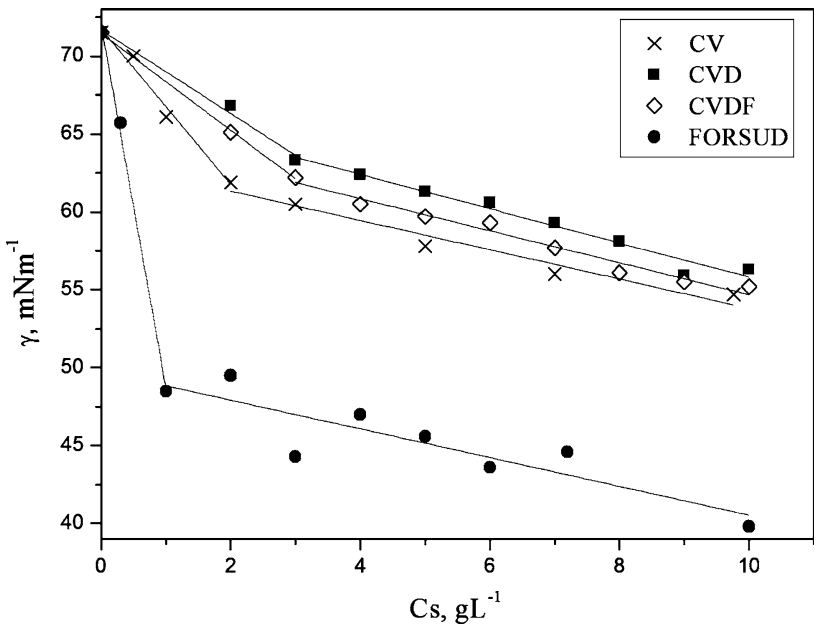

Fig. 1 Surface tension $(\gamma)$ vs. added SBO concentration (Cs)

observed in the majority of cases demonstrate that the linear fits are a good mathematical representation of the experimental $\gamma$-Cs plots. The data allow a more quantitative appreciation of the different behavior of the four investigated SBO. In essence, FORSUD SBO clearly gives the highest $\mathrm{d} \gamma_{1} / \mathrm{dCs}$ and the lowest $\mathrm{Cs}_{1}$ and $\gamma_{\mathrm{Cs}_{1}}$ values, whereas $\mathrm{CV}, \mathrm{CVD}$ and CVDF SBO do not seem to exhibit much difference one from the other.

Soil washing trials were performed at aqueous solution containing the SBO and the commercial Triton $\mathrm{X}-100$ surfactant at $50 \mathrm{~g} \mathrm{~L}^{-1}$ for comparison. Total PAHs concentration values, measured in the washing solutions after $24 \mathrm{~h}$ soil-solution contact time at 1:10 w/V solid/liquid ratio, were $10-37 \mathrm{mg} \mathrm{L}^{-1}$ for SBO and 36-240 mg L ${ }^{-1}$ for Triton X-100 solutions. These data clearly indicate the higher washing efficiency of the synthetic surfactant solution. For each SBO and Triton $\mathrm{X}-100$, a set of four consecutive washing runs with fresh solution aliquots were performed on the same soil sample recovered after each run. The \% w/w total PAHs recovered in the washing solutions relatively to the starting amount in the treated soil was found to decrease from one washing trial to the next. For each set of washing runs, total PAHs removed from soil was calculated from concentration values measured in the starting soil and in the soil recovered upon completion of the fourth washing run. The results reported in Fig. 2 indicate total PAHs removal from soil to be $94 \% \mathrm{w} / \mathrm{w}$ by Triton X-100, $48-57 \% \mathrm{w} / \mathrm{w} \%$ by CV, CVDF and CV SBO, not showing significant performance differences one from the other, and $32 \%$ by FORSUD SBO. 


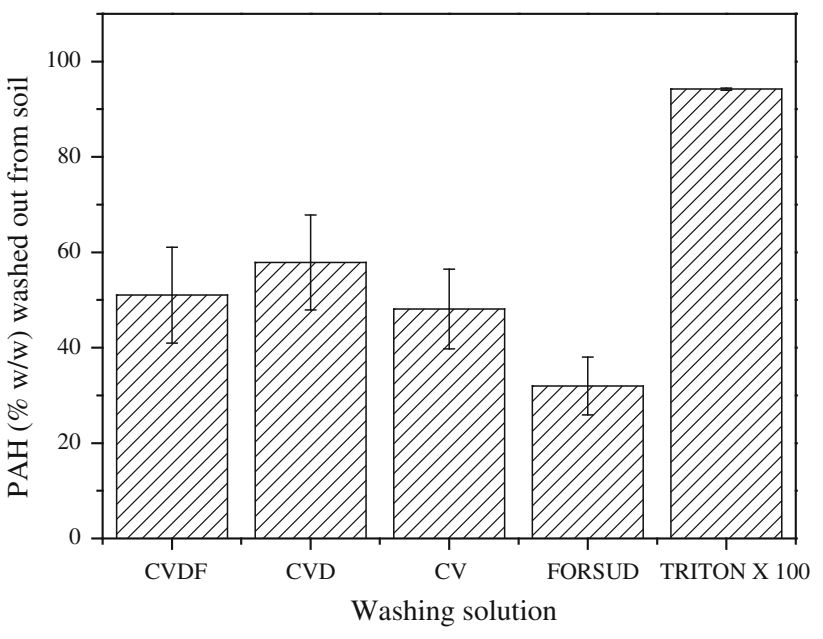

Fig. 2 Total PAHs removed from soil after four washings with the four investigated SBO and with Triton X-100: data are averages and standard deviations calculated over 12 samples per each SBO or Triton X-100, i.e. the three replicates performed on three different soil samples taken after the four consecutive washing runs performed on the same starting soil sample

Depletion of SBO and Triton X-100 from the washing solution due to absorption on soil was determined by measuring total organic C (TOC) concentration in the fresh and in the recovered washing solutions. The results are reported in Table 4. As PAHs concentrations in the washing solutions run at $0.001-0.02 \% \mathrm{w} / \mathrm{V}$ level, the TOC values are by large contributed from SBO or Triton X-100. The data show that no significant or major depletion of SBO or Triton occurs in the washing solutions after completion of the washing trials.

The 12 solutions recovered from each set of four washing runs performed in triplicates with $\mathrm{SBO}$ or Triton were pooled, acidified with $\mathrm{HCl}$ to $\mathrm{pH}<1.5$ and centrifuged to separate the supernatant liquid phase from the precipitated solid phase. The supernatant liquid phase was analyzed for PAHs and TOC and the \% abatement rates were calculated by the differences between the values found in the pooled solutions and in the supernatant liquid phase after precipitation. The results reported in Table 5 show that for all SBO solutions 96-99\% PAHs and $88-90 \%$ TOC removal is achieved by acidification and precipitation of the organic material. Under the same experimental conditions, for the Triton X-100 pooled solution samples no precipitation occurred and no significant PAHs and TOC removal was achieved.

For a comprehensive evaluation of all aspects of the above results, it should first be assessed whether the SBO might create a different contamination problem while remediating for PAHs. Based on their natural source, on
Table 4 Total organic C (TOC) measured in the fresh and recovered washing solutions containing the SBO and Triton $\mathrm{X}-100^{\mathrm{a}}$

\begin{tabular}{lll}
\hline & \multicolumn{2}{l}{ TOC, $\%$ w/V } \\
\cline { 2 - 3 } & Fresh solution & Recovered solution \\
\hline CVDF & $1.78 \pm 0.06$ & $2.12 \pm 0.76$ \\
CV & $1.71 \pm 0.06$ & $1.77 \pm 0.14$ \\
CVD & $1.74 \pm 0.06$ & $1.67 \pm 0.14$ \\
FORSUD & $2.02 \pm 0.06$ & $1.86 \pm 0.08$ \\
Triton X-100 & $4.01 \pm 0.12$ & $3.79 \pm 0.17$ \\
\hline
\end{tabular}

${ }^{a}$ Data for each recovered solution are averages calculated over 12 samples, i.e. the three replicates performed on three different soil samples taken after four consecutive washing runs performed on the same starting soil sample

Table 5 Abatement rate $(\% \mathrm{w} / \mathrm{w})^{\mathrm{a}}$ of PAHs and total organic $\mathrm{C}$ from Table 4 recovered washing solution by acidification at $\mathrm{pH}<1.5$

\begin{tabular}{lll}
\hline & \multicolumn{2}{l}{ Abatement rate, \% w/w } \\
\cline { 2 - 3 } & PAHs & TOC \\
\hline CVDF & $99.0 \pm 0.7$ & $87.8 \pm 0.8$ \\
CV & $96.1 \pm 2.6$ & $89.1 \pm 0.3$ \\
CVD & $95.5 \pm 2.2$ & $90.1 \pm 1.0$ \\
FORSUD & $97.4 \pm 0.6$ & $88.9 \pm 0.6$ \\
Triton X-100 & None $^{\mathrm{b}}$ & None $^{\mathrm{b}}$
\end{tabular}

${ }^{a}$ Data are averages calculated over triplicate measurements performed on the pooled solution aliquots recovered from each washing trial set performed on the same soil sample

b No PAHs and TOC abatement calculated since no precipitation by acidification occurred in the Triton X-100 recovered washing solutions

the structural similarities with NOM, and on the no adsorption by soil, no adverse environmental impact by SBO would be expected. Nevertheless, as shown in Table 1, they contain heavy metals and these might transfer from the washing solution to the soil. As reported in the "Introduction" section, the SBO have also been used as fertilizers in agriculture. According to Sortino et al. (2012), the SBO applied to soil at the rate of 3.8 ton $\mathrm{ha}^{-1}$ improve significantly tomato plant growth and fruit ripening and yield compared to commercial fertilizers. These authors have also evaluated the potential risk of soil contamination by the SBO heavy metals upon repeated application of these substances. On consideration of such application rates, and supposing that all metals contributed by SBO were accumulated in soil, with no removal occurring by plant adsorption, it was calculated that, in the top down to $30 \mathrm{~cm}$ depth soil, the heavy metal concentration increase contributed by SBO would be 
rather negligible relative to the normal heavy metal amounts in the starting soil and also to threshold heavy metal concentration values. In addition to this, phytotoxicity tests performed by Negre et al. (2012) have demonstrated that SBO are not phytotoxic, and that in some cases they promote the growth of probe species such as $R$. Sativus and S. Oleracea.

To evaluate how the results of this work will be applied in real-world situations, it should be considered that the UBW, sampled from different sections and process streams of a urban waste treatment plant, are readily available in most densely populated municipalities practicing modern waste treatment technology. Tables 1 and 2 data show that the four investigated UBW, by virtue of their different nature, yield a range of SBO differing for chemical nature and surface activity properties. Specifically, the digestate (FORSUD) recovered from the anaerobic digestion reactor of the organic humid fraction from separate source collection contains organic matter which, upon alkaline hydrolysis, yields a mix of relatively more lipophilic polymeric substances (FORSUD SBO) compared to the CVD, CVDF and CV SBO products obtained from composted wastes. The different chemical nature of these substances may be appreciated from the $\mathrm{LH}$ and Af/Ar indexes. These parameters show that FORSUD SBO has the highest relative content of lipophilic $\mathrm{C}$ atoms, contributed particularly by aliphatic $\mathrm{C}$ atoms. The relatively lower aliphatic $\mathrm{C}$ content of the other three SBO, and the higher content of oxidized $\mathrm{C}$ responsible of the lower $\mathrm{LH}$ value, seems consistent with faster mineralization rate of aliphatic $\mathrm{C}$ in the sourcing UBW and oxidation of residual lignin $\mathrm{C}$ under aerobic digestion conditions. In agreement with previous work (Montoneri et al. 2011b), the data reported for the SBO isolated from the composted UBW point out also the effect of the nature of the sourcing waste matter undergoing aerobic digestion. Indeed, CV SBO seems the most hydrophilic (lowest LH) and aromatic (lowest Af/Ar) product.

In addition to understanding the chemical composition of the SBO, for the scope of the present work it is important to understand also the solution behavior of these substances. The surface tension data in Fig. 1 and Table 2 are particularly useful to this end. Table 2 shows that, for each SBO, the slope value for the first descending tract of the $\gamma$-Cs plot $\left(\mathrm{d} \gamma_{1} / \mathrm{dCs}\right)$ is significantly higher than the value for the second tract $\left(\mathrm{d} \gamma_{2} / \mathrm{dCs}\right)$ by at least 1 order of magnitude. This fact points out that the SBO molecules are likely to undergo an important conformational change at the $\mathrm{Cs}_{1}$ concentration from a situation where the molecules occupy the water-air interphase to a molecular assembly occupying the bulk water phase. Therefore, further added surfactant molecules have very small or no effect on the water surface tension. Due to the change of polarity occurring from the air-water interphase to the bulk water phase, the molecules in the bulk water phase are expected to acquire a different conformation from those at the airwater interphase.

The different behavior between small molecule surfactants and the polymeric SBO in solution has already been discussed (Montoneri et al. 2010). With small molecule surfactants, it is easy to visualize solution conformational change between two situations occurring in solution. At the air-water interphase single molecules may be idealized lying orthogonal to the water surface, dipping their hydrophilic heads in the water phase and pointing their hydrophobic tails toward the air phase. In the bulk water phase, intermolecular interactions between single molecules are expected to yield more or less spherical or cylindrical micelles where the polar heads of each molecule are oriented toward the external water phase and the hydrophobic segments form the inner lipophilic core. Consistently with this interpretation, the surfactant concentration $\left(\mathrm{Cs}_{1}\right)$ at which the slope change occurs in the $\gamma-\mathrm{Cs}$ plot is denominated the critical micellar concentration (cmc). The $\mathrm{cmc}$ is taken as the surfactant concentration at which micelles start to form. For Cs increasing above $\mathrm{Cs}_{1}$, the concentration of micelles is supposed to increase.

With the polymeric SBO molecules, one could expect that the single molecules at the air-water interphase acquired a more or less flat configuration to point their hydrophilic heads toward the water phase. In the bulk water phase, two conformations are possible. In essence, single molecules may arrange in coil form to yield pseudo micelles with the external hydrophilic surface pointing toward the water phase and the inner lipophilic molecular segments away from it. The formation of pseudo micelles does not necessarily exclude the formation of molecular aggregates. Intermolecular ionic or H-bonding interaction between pseudo micelles are likely to occur and become more important at higher concentration. For the intended soil washing application of SBO, both the formation of pseudo micelles and/or larger macromolecular aggregates were important to enhance the kinetics and yield of the transfer of the PAHs contaminants from the soil to the aqueous washing solution. Indeed, by their surface activity the SBO were expected to enhance the water-soil contact. Also, by pseudo-micelle and/or aggregate formation in the bulk water phase, these macromolecules were expected to host the hydrophobic PAHs contaminants in the inner lipophilic core, and thus, to enhance 
their water solubility. Under this circumstance, preliminary soil washing trials were performed using the above SBO at $50 \mathrm{~g} \mathrm{~L}^{-1}$ Cs. This concentration was chosen to guarantee a high number of virtual micelles and/or molecular aggregates and at the same time to limit the water phase viscosity increase at higher Cs values. By comparison, also the commercial synthetic non ionic surfactant Triton X-100 was used under the same experimental conditions. This product, chemically named $p$-(1,1,3,3-tetramethylbutyl)phenoxypolyethoxyethanol and declared by the vendor to have average of 9.5 ethylene oxide units per molecule and molecular weight of $625 \mathrm{D}$ (Sigma Adrich 2012) is a powerful surfactant with $0.14 \mathrm{~g}$ $\mathrm{L}^{-1} \mathrm{cmc}$ (Shun Chia Industrial Company Limited 2012), capable to lower water surface tension down to $30 \mathrm{mN} \mathrm{m}^{-1}$ already at this concentration, and therefore, recognized as performance standard among similar products (Pramauro and Pelizzetti 1996; Wang et al. 2005). The analysis of the surface tension data (Table 2) against the chemical data (Table 1) leads to conclude that, among the investigated SBO, the most lipophilic FORSUD SBO is the most active biosurfactant, capable to lower the water surface tension down to about $40 \mathrm{mN} \mathrm{m}^{-1}$ at $10 \mathrm{~g} \mathrm{~L}^{-1} \mathrm{Cs}$ and giving the lowest $1 \mathrm{~g} \mathrm{~L}^{-1} \mathrm{Cs}_{1}$ value. Thus, compared to the other three biosurfactants at the same Cs value, FORSUD SBO for its surface activity and capacity to yield a higher number of virtual lipophilic micelles at $\mathrm{Cs}>\mathrm{Cs}_{1}$ was expected to yield the highest PAHs extraction yield in the soil washing case investigated in this work.

The selected urban soil, characterized by the data in Table 3, was a rather challenging case for several reasons. The soil had a rather high organic $\mathrm{C}$ and PAHs content. In addition, it had been exposed for over 100 years to pollution from coal refinery activity for the production of urban gas fuel. For the herewith investigated surfactant assisted soil washing process, the highly concentrated soil-organic matter (SOM) could in principle represent a favored solvent medium, hosting the PAHs contaminants for very long time. In this fashion, SOM could strongly hinder the PAHs transfer to the surfactant aqueous washing solution and, also, adsorb the added surfactant from the washing solution, causing further reduction of the efficiency of the remediation process. Transfer of SOM to the added surfactant washing solution is highly unlike since the former needs treatment in relatively strong alkaline conditions to become soluble (Tan 2011). Under these circumstances, the $5 \% \mathrm{w} / \mathrm{V}$ concentration, chosen for the SBO and Triton washing solutions used in this work, was expected to provide an aqueous medium which could well compete with SOM for the PAHs soil-water partition. Indeed, the surfactants' concentration was close to the concentration of organic matter in the starting soil (Table 3) and also guaranteed the presence of a high number of virtual micelles.

The data in Fig. 2 show that although the commercial synthetic Triton X-100 surfactant allows the highest $94 \%$ w/w PAHs removal from the investigated soil, the SBO biosurfactants exhibit also good performance yielding 30-57\% PAHs removal under the same experimental conditions. The higher performance of the commercial surfactant was expected on basis of its higher surface activity, very low $\mathrm{cmc}$ and higher number of micelles at the chosen $5 \%$ operating Cs value. Nevertheless, comparing SBO one another, it appears that, contrary to the expectations based on surface activity $\left(\gamma\right.$ and $\left.\mathrm{Cs}_{1}\right)$ and lipophilicity level (LH), FORSUD SBO yields the lowest PAHs recovery (Fig. 2). Cross-checking Fig. 2 data against Af/Ar and LH data in Table 1, one can observe that the type of lipophilicity (i.e. the Af/Ar parameter), more than the lipophilicity degree (LH), seems to affect the SBO performance in the present case study. Indeed, the CV, CVD and CVDF SBO, compared to FORSUD SBO, contain more aromatic $\mathrm{C}$ and allow almost $2 \times$ higher extraction efficiency, notwithstanding their lower lipophilicity degree (LH).

Particularly important are the data in Tables 4 and 5 for a comprehensive evaluation of the SBO performance. This should account also for the potential environmental impact arising from the surfactant adsorption by the soil and for the disposal of the recovered washing solution containing PAHs. Table 4 data do not evidence any important organic matter depletion in the washing solutions recovered from the soil treatment. Thus, surfactant adsorption by the soil does not seem to be a critical point, either for SBO and Triton X-100. Table 5, however, shows that SBO allow removing PAHs from the recovered washing solution by a very simple and fast chemical treatment: i.e. by precipitation at acid $\mathrm{pH}$ and separation of the clean aqueous solution from the solid phase containing the biosurfactant and the PAHs. The same does not occur for the Triton X-100 washing solution. The interesting performance of SBO in soil washing is the result of several favorable chemical and physical features present at the same time. These allow performing according to the following reaction scheme

$$
\begin{aligned}
& \text { Soil-PAHs }+\mathrm{SBO}(\mathrm{COOM})_{\mathrm{aq}} \\
& \quad \rightleftarrows \text { soil }+\mathrm{PAHs}-\mathrm{SBO}(\mathrm{COOM})_{\mathrm{aq}} \\
& \text { PAHs-SBO }(\mathrm{COOM})_{\mathrm{aq}}+\mathrm{HCl}_{\mathrm{aq}} \\
& \quad \rightleftarrows \downarrow \mathrm{PAHs}-\mathrm{SBO}(\mathrm{COOH})+\mathrm{MCl}_{\mathrm{aq}}
\end{aligned}
$$


In essence, in reaction 1 the biosurfactant in water soluble alkali metal $(\mathrm{M})$ carboxylate form $\left[\mathrm{SBO}(\mathrm{COOM})_{\mathrm{aq}}\right]$, by its aromatic lipophilic chemical nature and capacity to micellize, extracts the aromatic PAHs contaminants from soil to yield the PAHs-SBO $(\mathrm{COOM})_{\mathrm{aq}}$ water soluble aggregate. This aggregate is chemically very stable and, due to its macromolecular nature, precipitates at acid $\mathrm{pH}$ to yield (reaction 2) the water insoluble PAHs-SBO $(\mathrm{COOH})$ polymeric aggregate mix in carboxylic acid form. The data in Table 5 demonstrate that reaction 2 occurs with high yield.

By comparison, for the better surface activity properties, Triton X-100 allows higher PAHs removal from soil, yielding in the corresponding reaction 1 the water soluble PAHs-Triton $_{\mathrm{aq}}$ aggregate. However, this non ionic aggregate lacks the chemical features required for precipitating by acidification as the PAHs-SBO $(\mathrm{COOM})_{\text {aq }}$ aggregates do in reaction 2 . Thus, contrary to using the commercial Triton X-100 surfactants, the isolation of the solid PAHs$\mathrm{SBO}(\mathrm{COOM})_{\mathrm{aq}}$ aggregate allows to envision a possible final disposal by incineration of the PAHs recovered in solid form in step 2.

It is well known to specialist in the field of soil remediation that these same results might not be reproduced with different soil. Particularly, the soil washing step exemplified by the equilibrium reaction 1 will depend on the soil-soluble organic substances interaction, which in turn is affected by the chemical and physical properties of the soil. There is plenty of literature covering the field of soil washing. However, experimental data are difficult to compare since the tested surfactants and soils are widely different. Thus, discussion of the results of this work according to their similarity or contrast with those published by other authors could only be speculative. In this work, we have discussed the potential that the high content of soil-organic matter may have in the present case study. However, in addition to the organic matter content and type, other soil parameters may affect the soil washing process efficiency i.e. $\mathrm{NH}_{4}{ }^{+}$and $\mathrm{NO}_{3}{ }^{-}$ions, $\mathrm{pH}$, clay content, clay type, and several other physico-chemical features. A sound discussion of the effects of all of these parameters requires more data collected using the same SBO with different soils. Based on the promising results of this work, such investigation appears worthwhile to be pursued in future work aiming to product and process optimization tailored to specific cases and to the scale-up of this technology to commercial scale.

\section{Conclusion}

This paper addresses two important environmental issues: the management of urban wastes and the remediation of contaminated industrial sites. It proposes biowastes as renewable sources of soluble organic substances (SBO) with surface activity properties to use for remediation of soil contaminated by polycyclic aromatic hydrocarbon (PAHs). It also proposes a novel process. The collected experimental data offer intriguing perspectives for the development of a comprehensive SBO based soil remediation technology which included recycling and/or disposing of the solid organic residue and the acid salt solution produced in reaction 2. For the specific case of PAHs removal from soil, the type more than the degree of lipophilicity appears to affect the yield of reaction 1, while reaction 2 does not seem to depend on the type of biosurfactant. However, the whole body of Tables 1, 2 and Fig. 1 data demonstrate that biowastes, readily available in urban areas, may provide a wide range of ecofriendly biosurfactants. These, by virtue of their chemical differences, may be used to tailor the above two stage process to the contaminant to be removed. Under these perspectives, UBW should not be considered solely as an economic and environmental burden for society, but also as a readily available mean to cope with the environmental impact of industrial activities.

Acknowledgments This work was supported by Cipe 2006 and MISEICECRUI 2007 funds.

\section{Nomenclature}

SBO Soluble bioorganic substances

UBW Urban biowastes

FORSU Organic humid fraction of urban refuse obtained by separate source collection

FORSUD Digestate from FORSU anaerobic digestion

CV Compost obtained from urban gardening and park trimming residues (V)

CVD Compost obtained from FORSUD and V mix aged for 110 day

CVDF Compost obtained from FORSUD, $\mathrm{V}$ and municipal sewage sludge (F) mix aged for 110 days

Af/Ar Aliphatic to total aromatic $\mathrm{C}$ ratio

NOM Natural soil-organic matter

PAHs Polycyclic aromatic hydrocarbons

UF Ultrafiltration

$\gamma \quad$ Surface tension

Cs Added surfactant concentration

LH Lipophilic/hydrophilic C ratio

\section{References}

Avetta P, Bianco Prevot A, Fabbri D, Montoneri E, Tomasso L (2012) Photodegradation of naphthalenesulfonic compounds in the 
presence of a bio-waste derived sensitizer. Chem Eng J 197:193-198

Baboshin MA, Golovleva LA (2012) Aerobic bacterial degradation of polycyclic aromatic hydrocarbons (PAHs) and its kinetic aspects. Microbiology 81:639-650

Bremner DH, Burgess AE, Chand R (2011) The chemistry of ultrasonic degradation of organic compounds. Curr Org Chem 15:168-177

Chang SY, Li XP (2009) Modeling chlorobenzene leaching from a landfill into a soil environment using particle filter approach. J Environ Inform 12(2):88-95, and references therein

Dermont G, Bergeron M, Mercier G, Richer-Laflèche M (2000) Soil washing for metal removal: a review of physical/chemical technologies and field applications. Chemosphere 41:1301-1305

Deshpande S, Shiau BJ, Wade D, Sabatini DA, Harwell JH (1999) Surfactant selection for enhancing ex situ soil washing. Water Res 33:351-360

Faithfull NT (2002) Methods in agricultural chemical analysis: a practical handbook. CABI Publishing, New York

Froehner S, de Souza DB, Machado KS, Falcão F, Fernandes CS, Bleninger T, Neto DM (2012a) Impact of coal tar pavement on polycyclic hydrocarbon distribution in lacustrine sediments from nontraditional sources. Int J Environ Sci Technol 9(2):327-332

Froehner S, Dombroski LF, Machado KS, Scapulatempo Fernandes C, Bessa M (2012b) Estimation of bioavailability of polycyclic aromatic hydrocarbons in river sediments. Int $\mathrm{J}$ Environ Sci Technol 9(3):409-416

Huang DL, Zeng GM, Jiang XY, Feng CL, Yu HY, Huang GH, Liu $\mathrm{HL}$ (2006) Bioremediation of Pb-contaminated soil by incubating with Phanerochaete chrysosporium and straw. J Hazard Mater 134(1-3): 268-276, and references therein

Jafvert CT (1996) Surfactants/Cosolvents. Technology Evaluation Report TE-96-02. US Environmental Protection Agency http:// purl.access.gpo.gov/GPO/LPS32633. Accessed 13 January 2013

Li JB, Liu L, Huang GH, Zeng GM (2006) A fuzzy-set approach for addressing uncertainties in risk assessment of hydrocarboncontaminated site. Water Air Soil Pollut 171(1-4):5-18, and references therein

Magnacca G, Laurenti E, Vigna E, Franzoso F, Tomasso L, Montoneri E, Boffa V (2012) Refuse derived bio-organics and immobilized soybean peroxidase for green chemical technology. Process Biochem 47:2025-2031

Ministero delle Politiche Agricole (1997). Metodi Ufficiali di Analisi Fisica del Suolo. D.M. del $1^{\circ}$ Agosto 1997. Gazzetta Ufficiale N. 204 del 2.09.97. http://www.consiglionazionalegeologi.it/cng www/AODocumento.asp?iddoc $=2842 \&$ idcat $=7$. Accessed 29 March 2012

Ministero delle Politiche Agricole (1999a) Metodi Ufficiali di Analisi Chimica del Suolo. D.M. del 13/09/99, 609. Gazzetta Ufficiale N. 248 del 21.10.99. http://www.crcnet.it/DOCS/DM-13-091999.pdf. Accessed 29 March 2012

Ministero delle Politiche Agricole (1999b) DM 13/09/1999 metodo VII.2. Determinazione del Carbonio Organico in Campioni di Suolo (Metodo Spinger-Klee). Gazz. Uff. Suppl. Ordin. $\mathrm{n}^{\circ} 248$ del 21/10/1999. http://www.crenet.it. Accessed 30 March 2012

Montoneri E (2007) Biochemenergy http://www.biochemenergy.it. Accessed 29 March 2012

Montoneri E, Boffa V, Savarino P, Perrone DG, Garlasco L, Ghezzo M, Gundersen SA, Raichur MA (2009) Biobased products from residual biomasses. In: Proceedings of the 24th International Conference on Solid Waste Technology and Management, Philadelphia, PA, USA, 15-18 March. The Journal of Solid Waste Technology and Management. Department of Civil Engineering, Widener University 1 University Place, Chester,
PA 19013-5792 USA. e-mail: solid.waste@widener.edu. http:// www.widener.edu/solid.waste Accessed 22 September 2012

Montoneri E, Boffa V, Savarino P, Perrone DG, Montoneri C, Mendichi R, Acosta E, Kiran S (2010) Behaviour and properties in aqueous solution of bio-polymers isolated from urban refuse. Biomacromolecules 11:3036-3042

Montoneri E, Mainero D, Boffa V, Perrone DG, Montoneri C (2011a) Biochemenergy: a project to turn a urban wastes treatment plant into biorefinery for the production of energy, chemicals and consumer's products with friendly environmental impact. Int $\mathbf{J}$ Global Environ Issues 11:170-196

Montoneri E, Boffa V, Savarino P, Perrone DG, Ghezzo M, Montoneri C, Mendichi R (2011b) Acid soluble bio-organic substances isolated from urban bio-waste. Chemical composition and properties of products. Waste Manage 31:10-17

Negre M, Mozzetti Monterumici C, Vindrola D, Piccone G, Perrone DG, Tomasso L, Montoneri E (2012) Horticultural and floricultural applications of urban wastes originated fertilizer. Compost Sci Util 20:150-155

Pazos M, Rosales E, Alcántara T, Gómez J, Sanromán MA (2010) Decontamination of soils containing PHAs by electroremediation: a review. J Hazard Mater 177:1-11

Pramauro E, Pelizzetti E (1996) Surfactants in analytical chemistry: applications of organized amphiphilic media. In: Comprehensive analytical chemistry, Chap 1, vol 31. Elsevier Science BV, Amsterdam

Presidente della Repubblica (2006) Norme in Materia Ambientale. Decreto Legislativo 152/2006 Gazzetta Ufficiale N. 88 del 14.4.2006, suppl. ord. N. 96. http://www.camera.it/parlam/leggi/ deleghe/06152dl.htm. Accessed 29 March 2012

Savarino P, Montoneri E, Bottigliengo S, Boffa V, Guizzetti T, Perrone DG, Mendichi R (2009) Biosurfactants from urban wastes as auxiliaries for textile dyeing. Ind Eng Chem Res 48(8):3738-3749

Savarino P, Montoneri E, Musso G, Boffa V (2010) Biosurfactants from urban wastes for detergents formulation: surface activity and washing performance. J Surfactants Deterg 13:59-68

Shun Chia Industrial Company Limited (2012) TRITON Nonionic Surfactant X-100. http://www.shunchia.com/doc/x100.doc. Accessed 30 March 2012

Sigma Adrich (2012) Product Information Sheet. http://www. sigmaaldrich.com/catalog/ProductDetail. Accessed 30 March 2012

Sortino O, Dipasquale M, Montoneri E, Tomasso L, Perrone DG, Vindrola D, Negre M, Piccon G (2012) Refuse derived soluble bio-organics enhancing tomato plant growth and productivity. Waste Manage 331(32):1788-1797

Tan KH (2011) Principles of Soil Chemistry, 4th edn. CRC Press, Boca Raton

United States Environmental Protection Agency (2007a) Semivolatile organic compounds by gas chromatography/mass spectrometry (GC/MS). Method 8270D Revision 4 February 2007. http:// www.epa.gov/wastes/hazard/testmethods/sw846/pdfs/8270d.pdf. Accessed 29 March 2012

United States Environmental Protection Agency (2007b) Pressurized fluid extraction (PFE). Method 3545a Revision 1 February 2007. http://www.epa.gov/osw/hazard/testmethods/sw846/online/3_ series.htm. Accessed 11 October 2012

Wang WZ, Feng JL, Wang HJ, Cui ZJ, Li GZ (2005) Effectiveness of surface tension reduction by nonionic surfactants with quantitative structure-property relationship approach. J Dispersion Sci Technol 26:441-447

Wu YW, Huang GH, Chakma A, Zeng GM (2005) Separation of petroleum hydrocarbons from soil and groundwater through 
enhanced bioremediation. Energy Sources 27(1-2):221-232, and references therein

Zhang BY, Huang G H, Chen B (2008) Enhanced bioremediation of petroleum contaminated soils through cold-adapted bacteria. Pet Sci Technol 26(7-8): 955-971, and references therein
Zhang SY, Wang QF, Xie SG (2012) Molecular characterization of phenanthrene-degrading methanogenic communities in leachatecontaminated aquifer sediment. Int $\mathrm{J}$ Environ Sci Technol 9(4):705-712 